\title{
Objectifying China, Imagining America: Chinese Commodities in Early America
}

Susan Kern

William \& Mary, sakern@wm.edu

\section{Recommended Citation}

Gemme, P. (2012). Caroline Frank, Objectifying China, Imagining America: Chinese Commodities in Early America. European journal of American studies.

This Article is brought to you for free and open access by the Arts and Sciences at W\&M ScholarWorks. It has been accepted for inclusion in Arts \& Sciences Articles by an authorized administrator of W\&M ScholarWorks. For more information, please contact scholarworks@wm.edu. 
Anna Mae Duane, editor. The Children's Table: Childhood Studies and the Humanities. Athens: University of Georgia Press. 2013. Pp. viii, 265. Cloth \$69.95, paper \$24.95, e-book \$24.95.

Over the last decade, the interdisciplinary study of children and childhood has resulted in a rich and provocative body of research, several new professional groups and scholarly journals, and even Ph.D. degree-granting programs. The field of childhood studies has therefore emerged as a strongly multidisciplinary area of scholarship and teaching in the humanities, and yet its subject often remains vague and contested. Is it concerned with the study of "real" children (whether historical figures or present-day kids) and their lived experience, or with a social construction imagined and desired by adults? Or is it always both at the same time? Furthermore, when we study children and childhood, do we inadvertently reify essentialist notions of the child? And if childhood studies has arrived belatedly compared to gender studies, visual and cultural studies, or performance studies and remains more fragmented and heterogeneous, then what can it learn from other areas in the humanities and perhaps also from the sciences? The appearance of The Children's Table: Childhood Studies and the Humanities, edited by Anna Mae Duane, is well timed to support the scholarly momentum of the last decade, but it is also poised to call for a reassessment of the terms of the field.

The book is divided into four major parts, containing short provocative essays by thirteen authors that tackle a broad variety of thematic questions. The first section explores the question of the "child" and his or her agency, rights, and legal status, and the essays, by Annette Ruth Appell, Lucia Hodgson, James Marten, and John Wall, come from scholars of law, literature, history, and ethics. The unsurprising refrain in this section is that adults hold power and define the systems that recognize childhood as a dependent status based on biological age. Wall, however, argues for childism-a movement he aligns with feminism-which would train a more self-critical eye on the role of age (like class, "race," gender, or sexuality) in scholarship about human experience. The second section examines discipline, development, and education. The American antebellum literary evidence in essays by Sophie Bell and Lesley Ginsberg is oddly juxtaposed with Roy Kozlovsky's discussion of post-World War II English architecture and design, even if they share some terrain around ethics, individuality, and training. The desire to understand childhood apart from physical institutional settings is at once admirable and curious, since school occupied so much of Anglo-American children's lives in the eras under discussion. Part three puts gender and sexuality in the forefront and poses questions around essentialism, sex, gender, and the child. Sarah Chinn and Susan Honeyman both explore the forceful political point that the child is often tacitly understood as asexual and heteronormative. Carol Singley's essay on literary adoption challenges romantic assumptions around "family" and genealogy, casting the adopted child as an ambivalent rather than heroic figure. While many of the essays offer potentially insightful readings and methodological possibilities, the final section of the book addresses the experience of thinking about the praxis of childhood studies and teaching it as a subject. Robin Bernstein's essay on the theoretical potential of the doll-like notion of "effigy" in performance studies makes for a lively consideration of both historical and current childhoods. Similarly, Karen Sánchez-Eppler's contribution analyzes a material document, an elaborate nineteenth-century card and detailed drawing, presumably by a child for a teacher and wrapped in a needlepoint cover, to show the potential of the child's everyday experience, agency, and awareness, as well as the scholar's investment in archival matter. The final essay in the book, by Lynne Vallone, an administrator in the only Ph.D.-granting childhood studies program in the U.S., argues for the viability of the subject while acknowledging the experience of graduate students facing an uncertain, discipline-hived job market.

Together these essays lay out the potential of childhood studies to provoke both established scholars and their students to revisit accepted notions of children's and adults' experiences growing up. While a few essays refer to the historiography of the field, more of them demand that we revisit the terms we currently use to describe and analyze children and childhood. In this sense, the volume offers a window onto a shifting methodological landscape of childhood studies. The texts are sophisticated and nuanced, but still well within reach of advanced undergraduates, making them especially useful for teaching. For example, Chinn takes the historicizing tendencies of the field (long dominated by historians and scholars of children's literature) to task for its lack of activism compared with gender studies or queer theory: "childhood studies seldom articulates a political mission. A historicist approach largely precludes this strategy" (p. 161). Whether or not this is entirely accurate, the provocation provides a welcome, classroom-friendly challenge.

It is, however, clear that this collection has not aimed for greater representation of current historical scholarship. For all the post- or transdisciplinarity on display, there are some curious blind spots. Carol Singley suggests that there is a "childhood studies approach" (p. 193) as if this were something singular or well defined, which strikes a false note in a book trying hard to complicate childhood studies as a methodologically diverse field. Similarly, the dominance within the volume of literary subject matter and the Americanist bent-only Kozlovsky's essay deals with a non-American context-implies that childhood studies is a field allied with American studies, when one of the largest scholarly groups, the Society for the History of Children and Youth, is robustly international. Furthermore, while Duane argues that childhood studies might become an "epistemological game changer" (p. 5) and a means for humanities scholars to converse with scientists over a biologically based notion of "child," there 
is little demonstration of how either the social sciences or hard sciences might respond to these analyses.

The Children's Table, nonetheless, makes it clear that the subjects of children and childhood are no longer marginal areas of scholarship and academic research. Although Duane invokes the metaphor of the children's table to acknowledge the secondary status of children seated together at makeshift places apart from adults at holiday dinners, she also emphasizes the dynamic and unpredictable place that the children's table can become. Indeed, if the organizing metaphor of the children's table is just that, a metaphor rather than a study of the children's table as a material, historical, and sociological theme, then it also provides a means for scholars in and around several fields to sit together. Building on earlier scholarship that established many of the terms for thinking about children and childhood, The Children's Table successfully challenges us to reconsider our assumptions and the methods we employ, and to ponder the possibilities of a field in the process of growing up.

Amy F. Ogata

Bard Graduate Center

Mark Salber Phillips. On Historical Distance. New Haven, Conn.: Yale University Press. 2013. Pp. xvii, 293. $\$ 50.00$.

Distance is in, it seems! Historical proximity and historical teleology are out! Not only does Mark Salber Phillips here provide a richly nuanced analysis of how historians cope with the "otherness" of the past, but in literary studies, Franco Moretti has very recently collected his observations under the title Distant Reading (2013). It is all reminiscent of the celebrated dictum from L. P. Hartley's 1953 elegiac novel The Go-Between: "The past is a foreign country: they do things differently there" (p. 1). And indeed, this quotation, described as "the historian's motto," appears early in Phillips's account (p. xii).

An awareness of distance is particularly important to drum into newcomers to historical studies. On the other hand, exactly how distant is the past? Some features of history persist through time. The human genome, or set of genetic information for Homo sapiens, is something that coexists with all humans. It is true that its origins stem from an immensely long-term genetic evolutionary process. Thus when the human genome diverged from that of our close genetic relatives, the human sense of smell weakened in comparison with that of other mammals. Yet that divergence occurred so long ago as to constitute now a human norm. The genome is part of the here-and-now, not the "dead past."

In effect, the balance between continuity and change is never static. Culturally speaking, one person's admirable tradition to uphold is another's nightmare oppression to overthrow. Aspects of history that once seemed permanent may turn out to be adaptable, after all-and sometimes, indeed, vice versa: aspects that are thought of as "socially constructed" may turn out to be strangely resistant to revamping.

Certainly, enough things survive unequivocally through time to make "living history" into a valid counterpoint to the "dead past." Distance is not the whole story. Hartley's dictum is thus challenged by a rival, which also comes from another elegiac novel. William Faulkner's Requiem for a Nun (1951) declares: "The past is never dead. It's not even past" (p. 92). Discuss!

Phillips approaches these issues by exploring how scholars learned to appreciate and to represent historical distance at different times in the past. The combined effect of so much detail is almost too much; but specialists will appreciate his myriad of case histories.

Three large sections are presented, focusing upon broad moments. The first, circa 1500, works well. It is comparatively brief, highlighting the contrasting historical approaches of Niccolò Machiavelli and Francesco Guicciardini, who launched a new Florentine tradition. Old-style chronicles were turned into considered histories. All this makes the point that serious scholarship preceded the European intellectual ferment known as the Enlightenment. Yet Phillips is not in quest of "origins," which he considers an unhelpful approach. Instead, he demonstrates plurality as Machiavelli and Guicciardini, with their different intellects, framed contrasting histories. There was no one "right" way.

A second, much longer section tackles the production and representation of history in largely British scholarship and historical paintings circa 1800. These chapters are much more heavy-laden and almost unbalance the book. Pride of place is given to David Hume for his blend of historical irony and sentiment (while the oftpraised Edward Gibbon does not even make it into the index). Then follow discussions of contemporary and subsequent responses to Hume. Contrasting narratives are explored, including Thomas Carlyle's Past \& Present (1843) and Augustus Pugin's Contrasts (1836)_indicating that the nodal date of 1800 is very generously defined. Historical paintings and literary scholarship are also discussed as offering alternative vehicles for bringing the past "alive," but keeping it suitably distant.

Lastly, a third, shorter section focuses on circa 1968 and what Phillips sees as the contemporary stress upon studying affective experience and everyday life. Here his exemplars are drawn from later-twentieth-century Western scholarship and museumology. A study like The Presence of the Past: Popular Uses of History in American Life (1998) by Roy Rosenzweig and David Thelen represents the "sentimental mood" post-1968. Here "distance" is clearly at risk of succumbing to historical proximity. Indeed, the remembered past may become too cozy. It is vital to access difficult aspects of history (conflict, wars, hatred, resistance) in order to avoid either condescending to the past or prettifying it. Somewhat strangely, the Marxist historical tradition, the recent turn to global affairs, and Big History are not discussed, even though all these approaches are very concerned with distance. But that rather makes Phillips's point. History-writing is such a pluralist endeavor 